\title{
The Effects of Tetrodotoxin, Papaverine and Verapamil on the Increase in the Rate of Spontaneous Afferent Discharges Induced by Local Anesthetics from the Pulmonary Mechanoreceptors of the Bullfrog
}

\author{
Hitoshi KONTANI and Ryozo KOSHIURA \\ Department of Pharmacology. Hokuriku University. School of Pharmacy. \\ Ho-3 Kanagawa-machi, Kanazawa 920-11, Japan
}

Accepted September 17. 1984

\begin{abstract}
Procaine $\left(1 \times 10^{-5}-1 \times 10^{-4} \mathrm{M}\right)$, dibucaine $\left(1 \times 10^{-5}-1 \times 10^{-4} \mathrm{M}\right)$ and tetracaine $\left(1 \times 10^{-6}-1 \times 10^{-5} \mathrm{M}\right)$ caused an increase followed by a decrease in the rate of spontaneous afferent $(A)$ discharges (D) accompanied with a decrease in the flow rate of perfusion solution from the pulmonary vein in the isolated lung of the bullfrog, but these local anesthetics only decreased the rate of A.D. synchronized with lung inflation. The stimulatory effects of these drugs on the rate of spontaneous A.D. were studied. In the presence of TTX $\left(1 \times 10^{-7} \mathrm{M}\right)$, the increase in the rate of spontaneous A.D. by local anesthetics was inhibited, but the decrease in the flow rate of perfusion solution by these drugs was not inhibited. Papaverine $\left(1 \times 10^{-5} \mathrm{M}\right)$, which inhibited the decrease in the flow rate of perfusion solution by these local anesthetics, inhibited the increase in the rate of spontaneous A.D. by dibucaine, but not those by procaine and tetracaine. The inhibitory effects on the increase in the rate of spontaneous A.D. by these local anesthetics could be seen with verapamil in a concentration $\left(1 \times 10^{-4} \mathrm{M}\right)$ which significantly inhibited the rate of spontaneous A.D., like TTX $\left(1 \times 10^{-7} \mathrm{M}\right)$. Verapamil could not reverse the decrease in the flow rate of perfusion solution by these local anesthetics. From these results, the increase in the rate of spontaneous A.D. by procaine and tetracaine is due to not only the contractile effects of the drugs on the pulmonary vessel but also the direct stimulatory effects on the receptors which generate spontaneous A.D., and the increase in the rate of spontaneous A.D. by dibucaine may result from the contraction of the pulmonary vessel, and the stimulatory effect of dibucaine on the receptors would be weaker than that of procaine and tetracaine, since dibucaine could cause the increase in the rate of spontaneous A.D. only when dibucaine decreased the flow rate of perfusion solution.
\end{abstract}

Previously, we (1) reported that some local anesthetics (procaine, tetracaine and dibucaine) increased the rate of spontaneous afferent (A) discharges (D) from the pulmonary mechanoreceptors which was accompanied by a decrease in the flow rate of perfusion solution from the pulmonary vein, but tetrodotoxin (TTX) and chlorpromazine. which did not change the flow rate of perfusion solution, only decreased both rates of A.D. in the perfused lung of the bullfrog. From these results, it was suggested that the increase in the rate of spontaneous A.D. induced by local anesthetics would result from the stimulation of the mechanoreceptors on the pulmonary vessel when the vessel was contracted by local anesthetics (1). On the other hand, since procaine was reported to have a depolarizing effect on the pulmonary artery $(2,3)$, there is the possibility that the local anesthetics directly depolarize the mechanoreceptors. In order to clarify the mechanisms of the increase in the spontaneous A.D. induced by these local 
anesthetics, we compared the effects of local anesthetics and aconitine on the rate of spontaneous A.D. in the presence of TTX and smooth muscle relaxants (papaverine and verapamil), since it was reported that aconitine directly depolarized the crayfish stretchreceptor and the action of aconitine was inhibited by TTX (4). We also examined the drugs on the rate of A.D. synchronized with lung inflation and compared the effects of these drugs on the receptors which generated each A.D.

\section{Materials and Methods}

The experiments were performed on bullfrogs (Rana catesbeiana) weighing 250$350 \mathrm{~g}$. Preparations and recording methods were described in a previous paper (5). The right lung was excised together with the pulmonary branches of the right vagus nerve, and a tracheal cannula and an arterial cannula were inserted. The lungs were perfused with amphibian Ringer's solution $(\mathrm{pH} 7.5 \pm 0.2$. $20^{\circ} \mathrm{C}$ ). The lung was always inflated with an artificial respirator (Takahashi model TB-101) with air $(5 \mathrm{ml})$ at the rate of $3-4 / \mathrm{min}$ during the experiment. The A.D. were recorded from the pulmonary nerve branches placed on a pair of platinum electrodes. As the bundle of afferent fibers was placed on the recording electrodes, the discharges from some groups of receptors were recorded simultaneously. When the pressure in the lung was monitored with a pressure transducer (Nihon Kohden, MUP-0.5) attached to a branch of the rubber tube of the tracheal cannula and the pressure in the lung was almost zero, different amplitudes of spontaneous A.D. were recorded. According to a rise in the pressure in the lung, high frequency and different amplitude A.D.'s synchronized with lung inflation that were superimposed on spontaneous A.D. were recorded (Fig. 1). As we could not classify the spikes according to the amplitude, the spikes higher than an arbitrary threshold were then transformed into square wave pulses and fed into an integrator. The output of the integrator was recorded by a D.C. recorder (Hitachi 056) and was regarded as the frequency of generating A.D. When only the spontaneous A.D. were recorded, the tracheal cannula was disconnected from the artificial respirator. The amount of perfusion solution from the pulmonary vein was measured every min. When we investigated the effects of local anesthetics and aconitine in the presence of TTX, papaverine or verapamil on the rate of spontaneous A.D., TTX for $3 \mathrm{~min}$ and papaverine and verapamil for 5 min were applied beforehand, and then local anesthetics or aconitine was added in the solution which contained TTX, papaverine or verapamil.

Drugs used were procaine $\mathrm{HCl}$ (Bancain, Banyu Pharm. Co.), dibucaine $\mathrm{HCl}$ (Percamin, Nagase lyakuhin), tetracaine $\mathrm{HCl}$ (tetocain, Kyorin Pharm. Co.), TTX (Sigma), aconitine (Merck), papaverine (Wako Pure Chem.) and verapamil (a gift from Eisai). Each concentration of the drugs was examined at least in four different preparations. Student's $t$-test was used for a statistical comparison between mean values.

\section{Results}

1. The effects of TTX on the rate of spontaneous A.D. and the flow rate of perfusion solution induced by local anesthetics and aconitine: In Fig. 2 (I), only the spontaneous A.D. was recorded, and the effects of TTX $\left(1 \times 10^{-7} \mathrm{M}\right)$ and procaine $\left(1 \times 10^{-4} \mathrm{M}\right)$ on the spike amplitude and the rate of spontaneous A.D. were examined. When TTX or TTX and procaine were applied, spontaneous

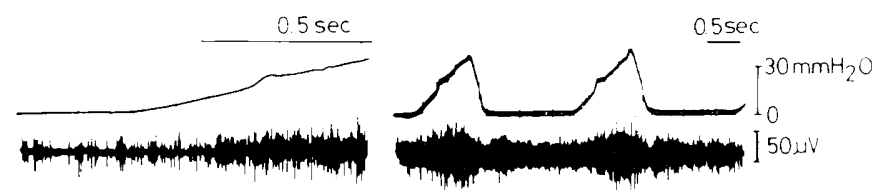

Fig. 1. The recordings of the pressure in the lung and the afferent discharges from the perfused bullfrog lung. For details, see method. Upper records: the pressure in the lung. Lower records: afferent discharges. 

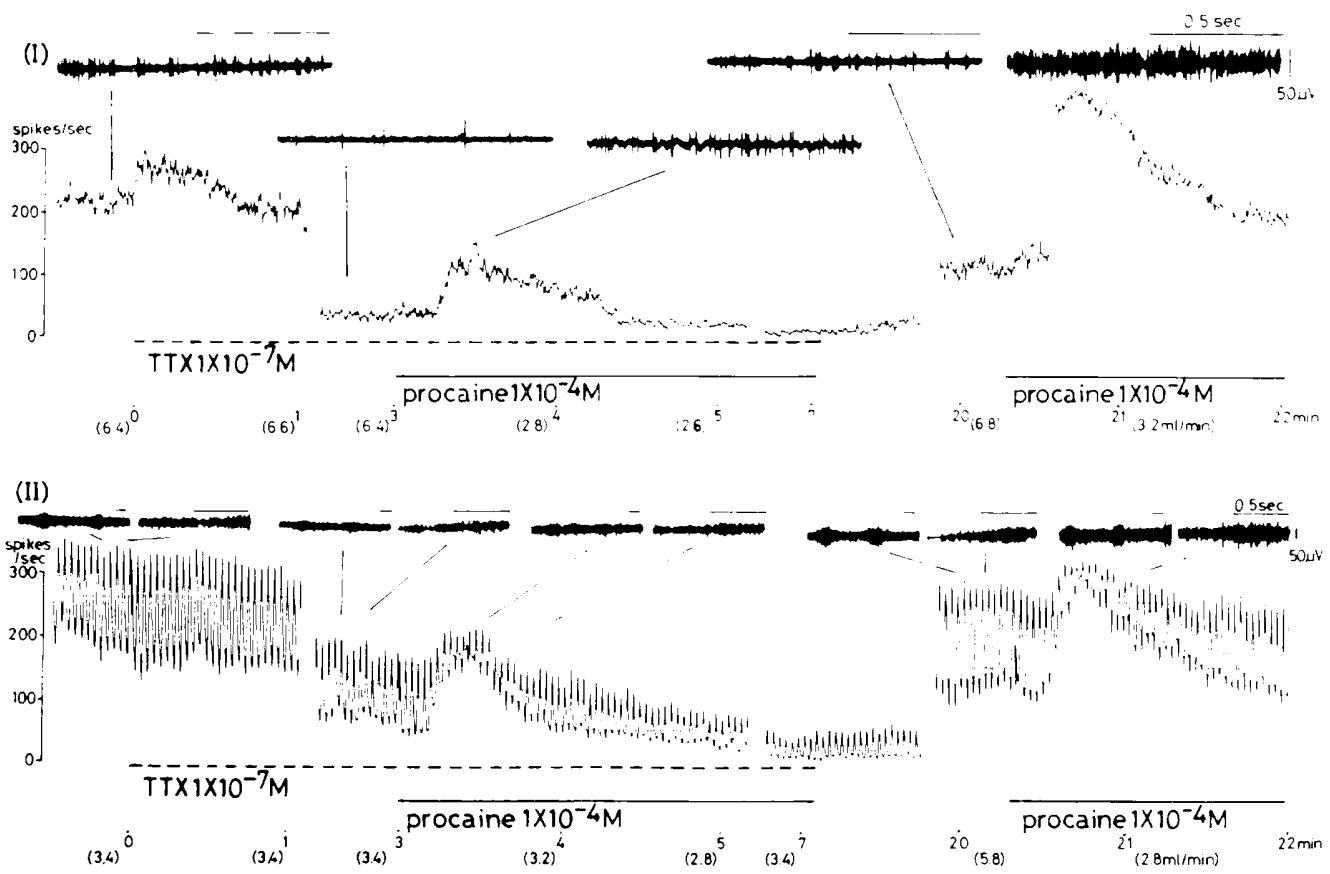

Fig. 2. The effects of procaine on the spike amplitude and the rate of spontaneous afferent discharges in the resting expiratory state of the perfused bullfrog lung (1) and the effects of procaine on the rate of spontaneous afferent discharges and the rate of afferent discharges synchronized with lung inflation with an artificial respirator (II) in the presence of TTX. In (1), the tracheal cannula was disconnected from the artificial respirator. In all experiments except (1), the lung was inflated with an artificial respirator during the experiment. The recording shows the spike frequency recorded by using an integrator and a [D.C. recorder. Vertical bar: the spike frequency of discharges. Solid and broken horizontal bar: time for perfusion of the solution containing drugs. Number in parenthesis indicates the amount of perfusion solution per min. Photographs of the oscilloscope display at different two sweep speeds are added when the experiment was done in the inflated lung.

A.D.'s which were different in amplitude could be seen but the spike amplitude was not significantly different from the amplitude which was seen before application of these drugs. When procaine was applied after washing out of TTX, high frequency spontaneous A.D. appeared. Most of these spikes were significantly higher, as compared to the spike amplitudes before application of drugs. It was thought that many spontaneous A.D. generated simultaneously in the presence of procaine and compound potentials were recorded. TTX suppressed the increase in the rate of spontaneous A.D. induced by procaine, as compared with the increase by reapplication of procaine after washing out of TTX and procaine. When the lung was inflated with an artificial respirator, TTX $\left(1 \times 10^{-7} \mathrm{M}\right)$ exerted similar inhibitory effects on the spontaneous A.D. increased by procaine which were seen in the resting expiratory states of the lung (Fig. 2 II). However, the rate of A.D. synchronized with lung inflation was decreased by these drugs, while the significant increase in the rate of spontaneous A.D. by procaine was suppressed by TTX (Fig. 2 II). We (1) reported that aconitine $\left(1 \times 10^{-6} \mathrm{M}\right)$ significantly increased the rate of spontaneous A.D. and irreversively abolished all A.D. in normal Ringer's solution (Fig. 3A). In the presence of TTX $\left(1 \times 10^{-7} \mathrm{M}\right)$, the stimulatory effect of aconitine $\left(1 \times 10^{-6} \mathrm{M}\right)$ on the rate of spontaneous A.D. was inhibited as compared with the effect of aconitine in normal Ringer's solution; and aconitine, like procaine, could 


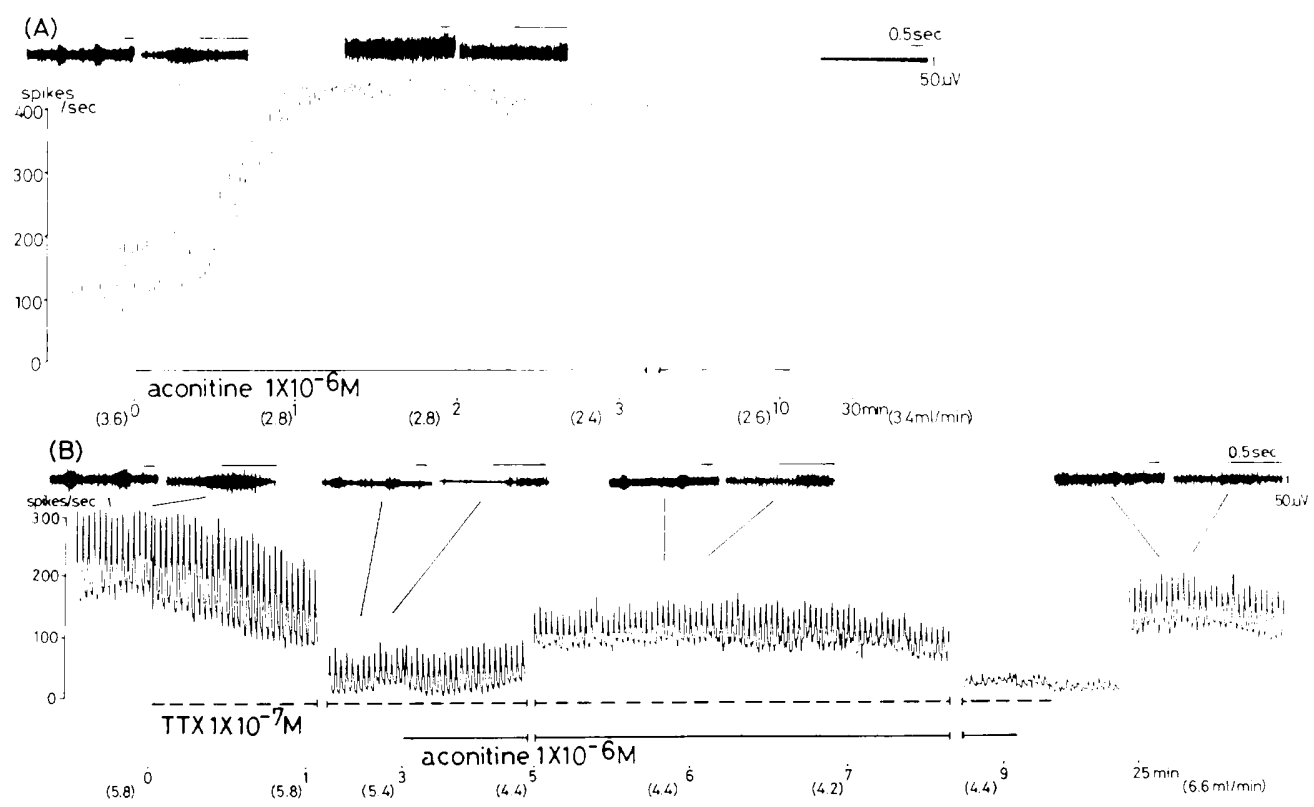

Fig. 3. The effects of acoritine on the rate of afferent discharges from the perfused bullfrog lung inflated with an artificial respirator in the normal Ringer's solution (A) and in the solution containing tetrodotoxin (TTX) (B). For details of legend, see Fig. 2.

not increase the rate of A.D. synchronized with lung inflation, while the significant increase in the rate of spontaneous A.D. was suppressed by TTX (Fig. 3 B). When aconitine was applied in the presence of TTX $\left(1 \times 10^{-7}\right.$ M), all A.D.'s finally disappeared, but high frequency spontaneous A.D. and very low frequency A.D. synchronized with lung inflation reappeared after washing out of TTX and aconitine $\left(1 \times 10^{-6} \mathrm{M}\right)$ (Fig. $3 \mathrm{~B}$ ). The effects of local anesthetics (procaine. dibucaine and tetracaine) and aconitine are summarized in Table 1. When procaine or tetracaine was applied in the absence or presence of TTX, the rate of spontaneous A.D. and A.D. synchronized with lung inflation were almost recovered after washing out of these drugs. TTX reduced the maximum rate of spontaneous A.D. increased by procaine $\left(1 \times 10^{-5}-1 \times 10^{-4} \mathrm{M}\right)$ and tetracaine $\left(1 \times 10^{-6}-1 \times 10^{-5} \mathrm{M}\right)$, as compared with the maximum rate by procaine or tetracaine reapplied after washing out of TTX and these drugs. Since the inhibitory effects of dibucaine on the rate of A.D. were irreversible and could not be recovered after washing out of dibucaine in the presence or absence of TTX (1), we compared the maximum rate induced by dibucaine in normal Ringer's solution with that in the presence of TTX. TTX reduced the maximum rate induced by dibucaine, but TTX did not affect the decrease in the flow rate of perfusion solution by these drugs.

2. Effects of papaverine: Figures 4 and 5 show that the effects of procaine and aconitine on the rate of A.D. and the flow rate of perfusion solution in the presence or after washing out of papaverine, and the results of local anesthetics and aconitine are summarized in Table 2. Papaverine $\left(1 \times 10^{-5}\right.$ M) caused a clear relaxation of the entire lung, but did not change the rates of spontaneous A.D. and A.D. synchronized with lung inflation significantly, but papaverine $\left(1 \times 10^{-5} \mathrm{M}\right)$ inhibited the decrease in the flow rate of perfusion solution by local anesthetics and aconitine and the increase in the rate of spontaneous A.D. by dibucaine (Table 2). The maximum rates of spontaneous A.D. increased by procaine and tetracaine in the presence and after washing 
Table 1. Effects of tetrodotoxin (TTX) on the rate of spontaneous afferent discharges and the flow rate of perfusion solution induced by local anesthetics and aconitine

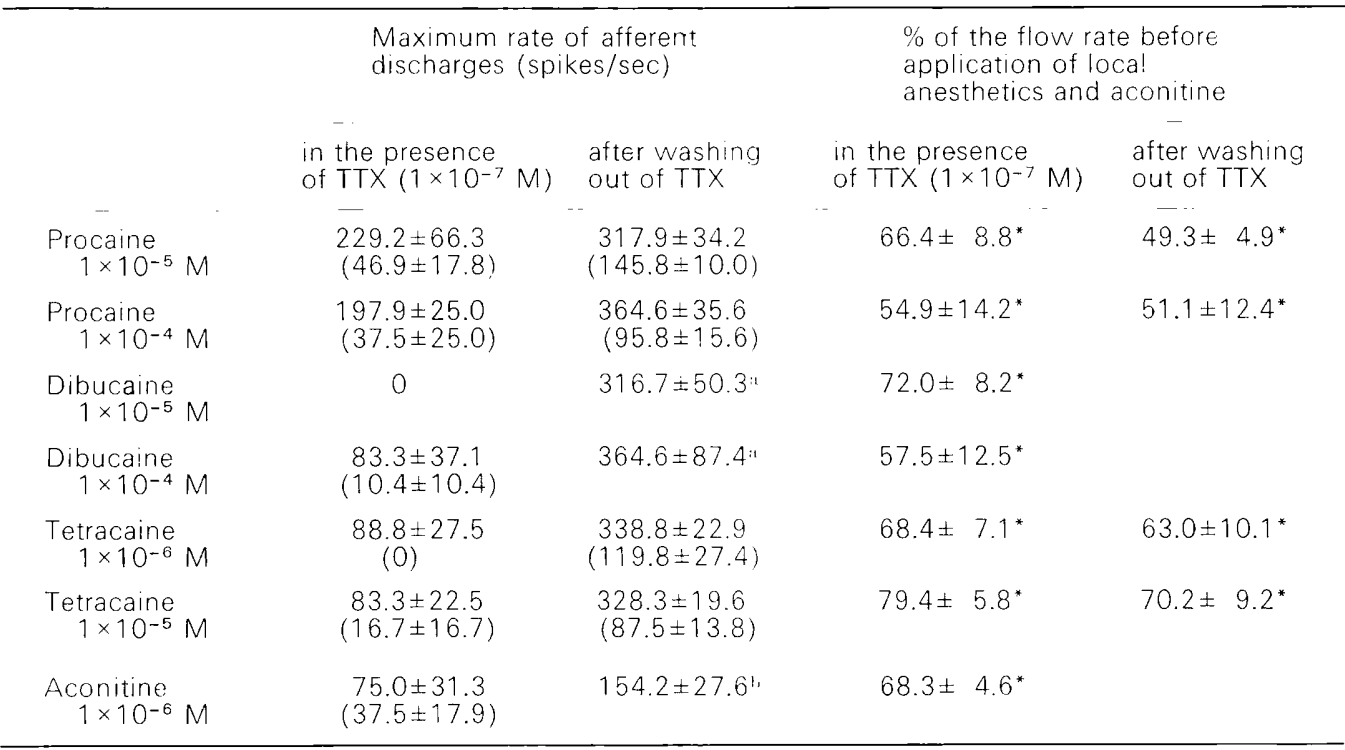

Each value represents the mean \pm S.E. of four experiments. Value " and Value "indicate the maximum rate of spontaneous afferent discharges increased by dibucaine in normal Ringer's solution and the maximum rate of spontaneous afferent discharges after washirg out of TTX and aconitine, respectively $(n=4)$. Number in parenthesis indicates the rate of spontaneous afferent discharges before application of local anesthetics or aconitine in the presence of TTX. ${ }^{*}: P<0.05$, significantly different from the flow rate obtained before application of local anesthetics or aconitine. Aconitine and dibucaine were applied in the presence of TTX, but were not applied after washing out of TTX.

out of papaverine $\left(1 \times 10^{-5} \mathrm{M}\right)$ were almost the same level. The effect of aconitine on the rate of A.D. in the presence of papaverine $\left(1 \times 10^{-5} \mathrm{M}\right)$ was very similar to that in normal Ringer's solution (Fig. 3).

Papaverine $\left(1 \times 10^{-4} \mathrm{M}\right)$ increased the spontaneous A.D., and then the rate returned to slightly below the level before application of papaverine within $5 \mathrm{~min}$ (Fig. 5). In the presence of papaverine $\left(1 \times 10^{-4} \mathrm{M}\right)$. procaine, tetracaine and aconitine slightly increased the rate of spontaneous A.D., but these drugs decreased the rate of A.D. synchronized with lung inflation and then abolished all A.D. After washing out of papaverine and local anesthetics, the rates of both A.D. were almost recovered, but the maximum rates increased by reapplied local anesthetics were lower than the maximum rates by local anesthetics reapplied after washing out of papaverine $\left(1 \times 10^{-5} \mathrm{M}\right)$ (Figs. 4, 5 and Table 2). After washing out of papaverine $\left(1 \times 10^{-4} \mathrm{M}\right)$ and aconitine, high frequency spontaneous A.D. reappeared as seen after washing out of TTX and aconitine (Fig. 5 and Table 2).

3. Effects of verapamil: Verapamil $\left(1 \times 10^{-5}\right.$ M) slightly inhibited the increase in the rate of spontaneous A.D. induced by local anesthetics at low concentration. Verapamil $\left(1 \times 10^{-4} \mathrm{M}\right)$ did not cause the relaxation of the entire lung, but it increased the rate of spontaneous A.D., like papaverine $\left(1 \times 10^{-4}\right.$ $M)$, and then decreased the rate of A.D. significantly within $5 \mathrm{~min}$ (Fig. 7). Verapamil at the concentration $\left(1 \times 10^{-4} \mathrm{M}\right)$ which decreased the rates of A.D. and inhibited the stimulatory effect of aconitine on the rate of spontaneous A.D., inhibited the stimulatory effect of local anesthetics at high concentration (Figs. 6 and 7 and Table 3). When verapamil $\left(1 \times 10^{-4} \mathrm{M}\right)$ inhibited the significant increase in the rate of spontaneous A.D. by local anesthetics and aconitine, the 


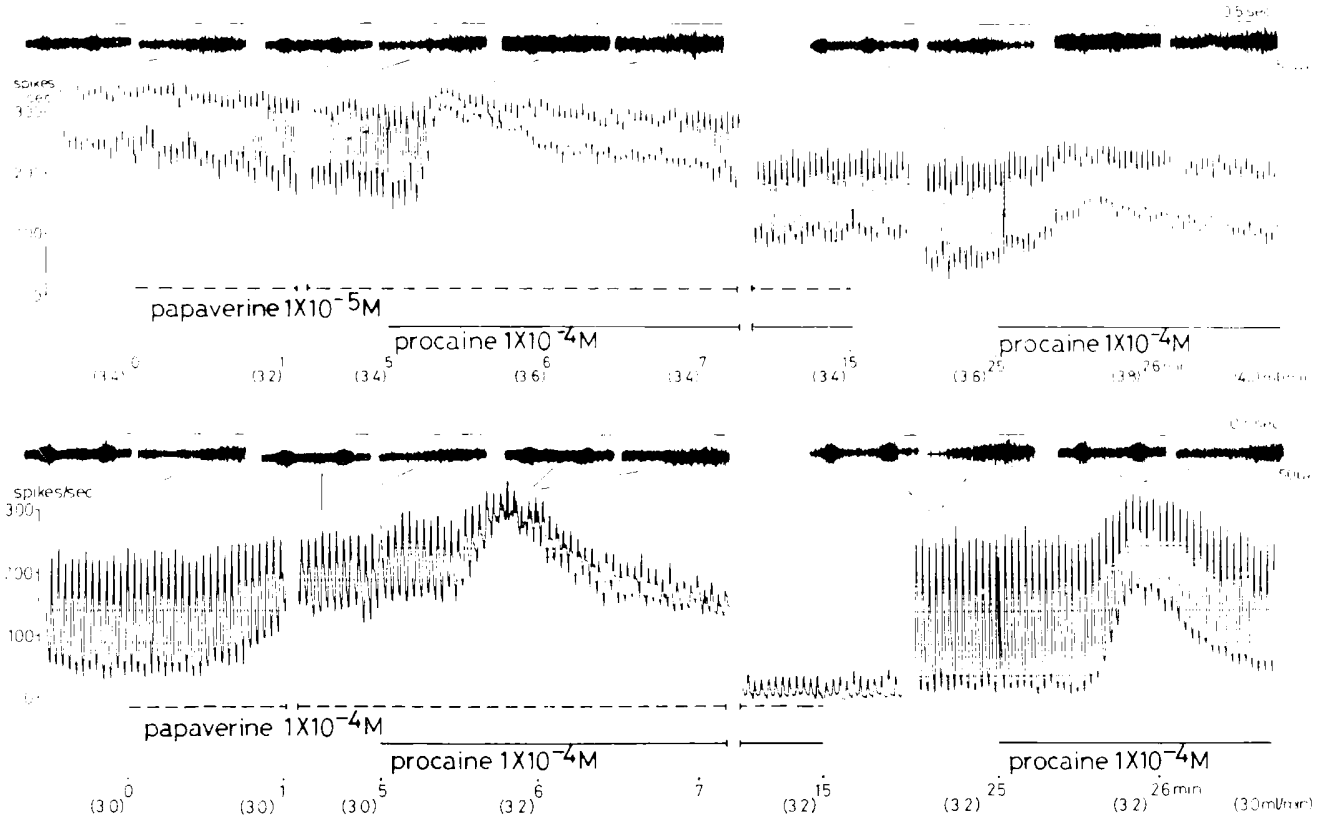

Fig. 4. The effects of procaine on the rate of afferent discharges from the perfused bullfrog lung inflated with an artificial respirator in the presence of papaverine. For details of legend, see Fig. 2.

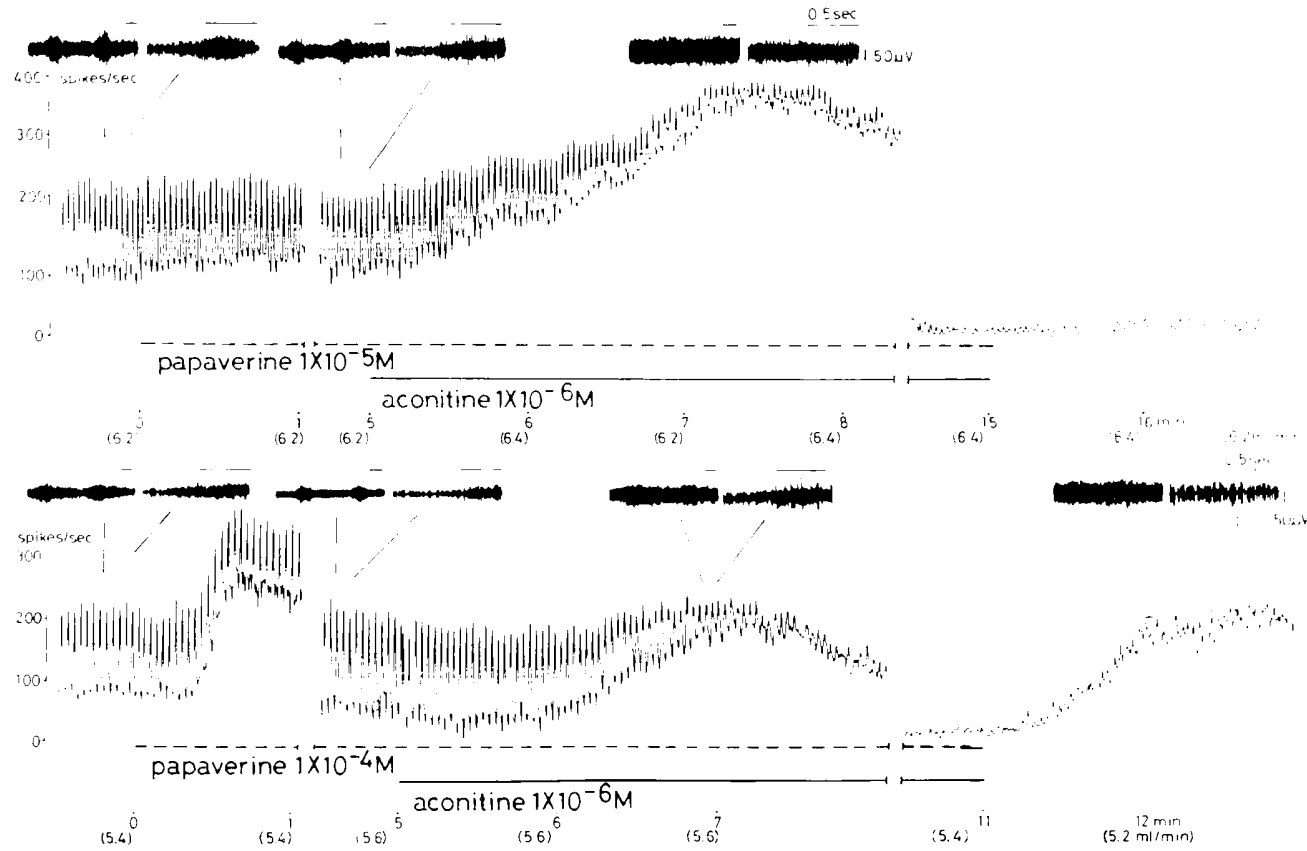

Fig. 5. The effects of aconitine on the rate of afferent discharges from the perfused bullfrog lung inflated with an artificial respirator in the presence of papaverine. For details of legend, see Fig. 2. 
Table 2. Effects of papaverine on the rate of spontaneous afferent discharges and the flow rate of perfusion solution induced by local anesthetics and aconitine

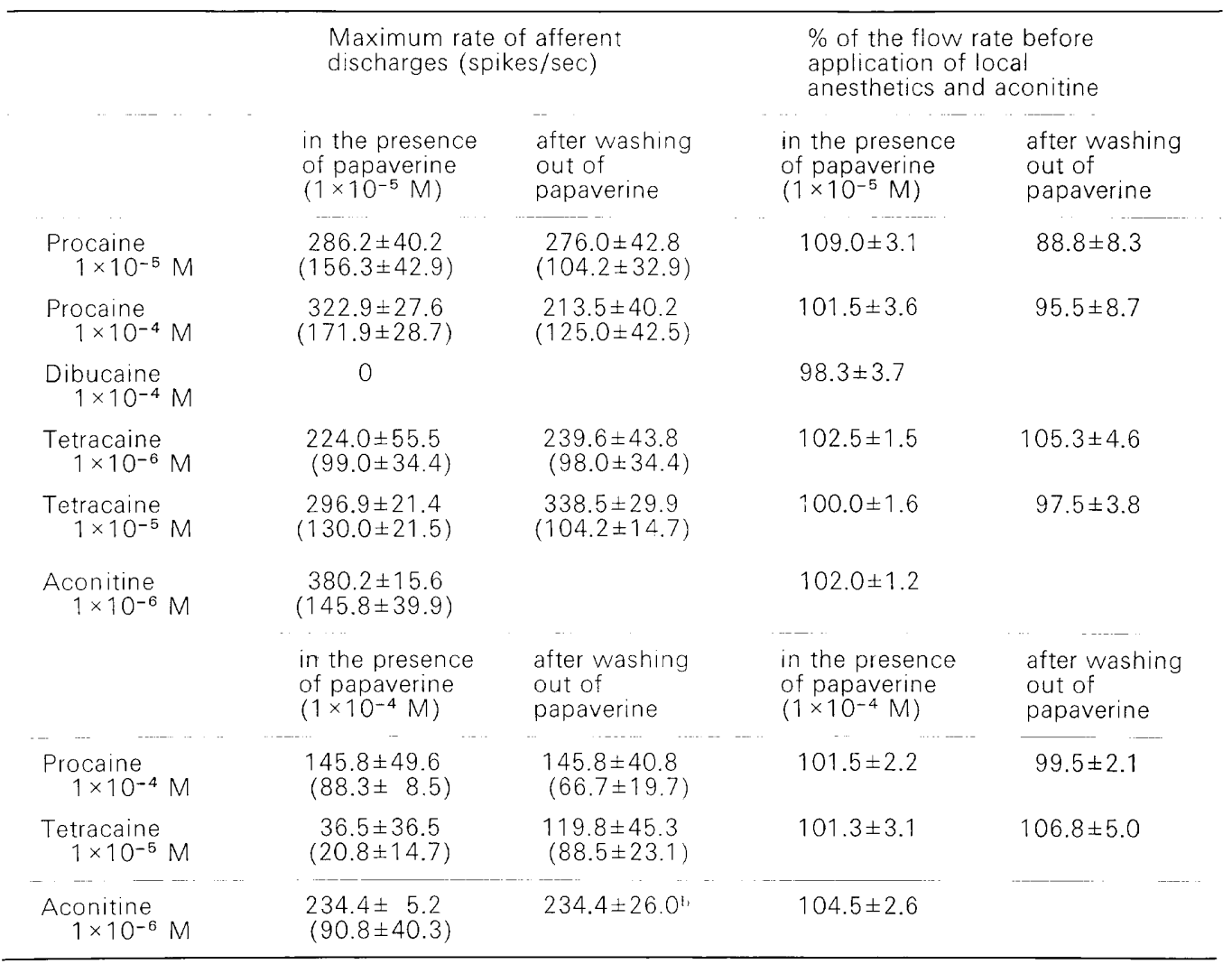

Each value represents the mean \pm S.E. of four experiments. Value ${ }^{b}$ iridicates the maximum rate of spontaneous afferent discharges after washing out of papaverine and aconitine. Number in parenthesis indicates the rate of spontaneous afferent discharges before application of local anesthetics or aconitine in the presence of papaverine. Aconitine and dibucaine were applied in the presence of papaverine, but were not applied after washing out of papaverine.

rate of A.D. synchronized with lung inflation was not increased by these drugs. The inhibition by local anesthetics and verapamil of the spontaneous A.D. and the A.D. synchronized with lung inflation was recovered by washing out, but in the case of aconitine, only the spontaneous A.D. reappeared after washing out (Fig. 7). Verapamil $\left(1 \times 10^{-4} \mathrm{M}\right)$ inhibited the decrease in the flow rate of perfusion solution by aconitine. but not those by local anesthetics (Table 3).

\section{Discussion}

Since the method we used recorded the afferent discharges from the bundle of afferent fibers, the output of the integrator did not exactly indicate the sum of numbers of spikes which were simultaneously generated from each receptor, but it could reflect the increase or decrease in the number of spikes. It was impossible for us to record only the A.D. synchronized with lung inflation. When the lung was inflated, high amplitude spikes were recorded. Most of the A.D.'s synchronized with lung inflation superimposed on the spontaneous A.D. (Fig. 1), and compound potentials would be recorded. Since our method preferentially recorded higher amplitude spikes, we regarded the amount of phasic change of the output of the integrator according to the lung inflation as the rate of A.D. synchronized with lung inflation. 

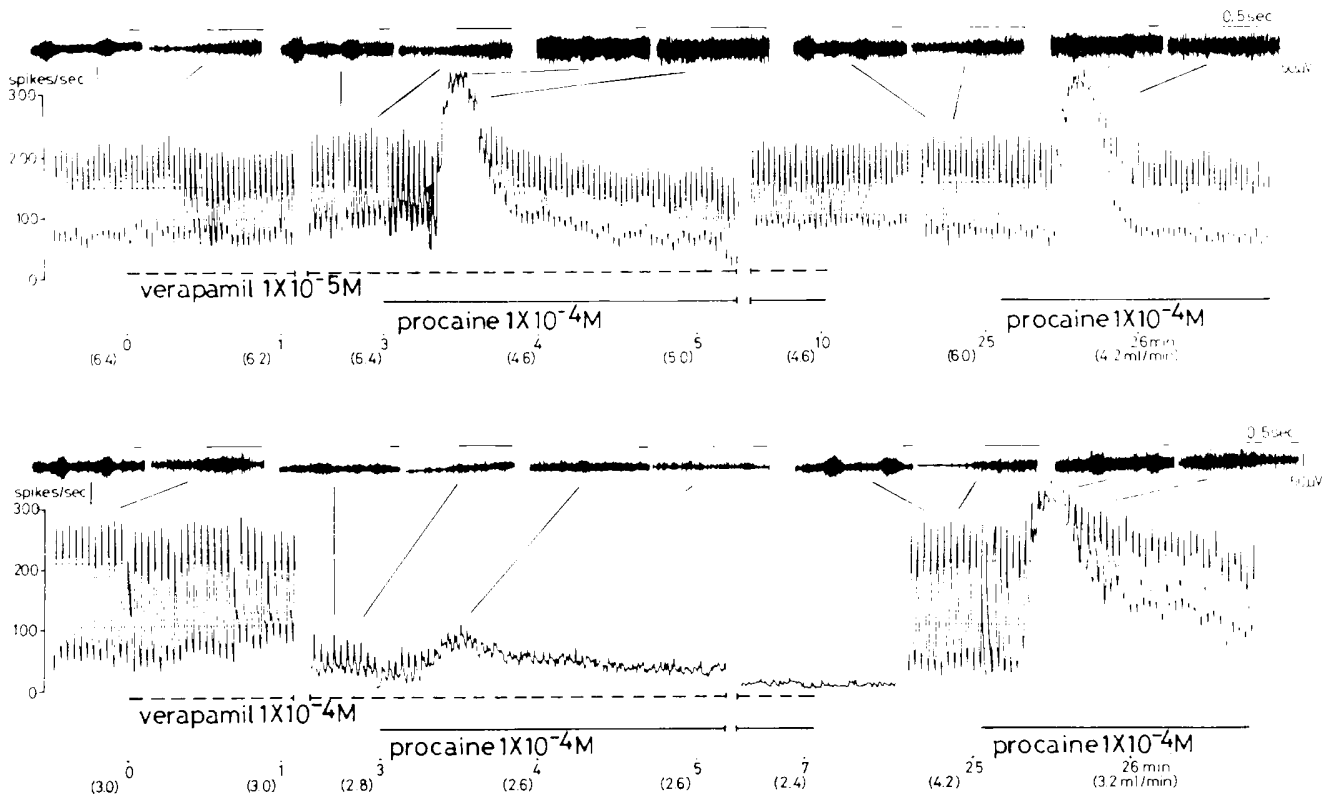

Fig. 6. The effects of procaine on the rate of afferent discharges from the perfused bullfrog lung inflated with an artificial respirator in the presence of verapamil. For details of legend, see Fig. 2.

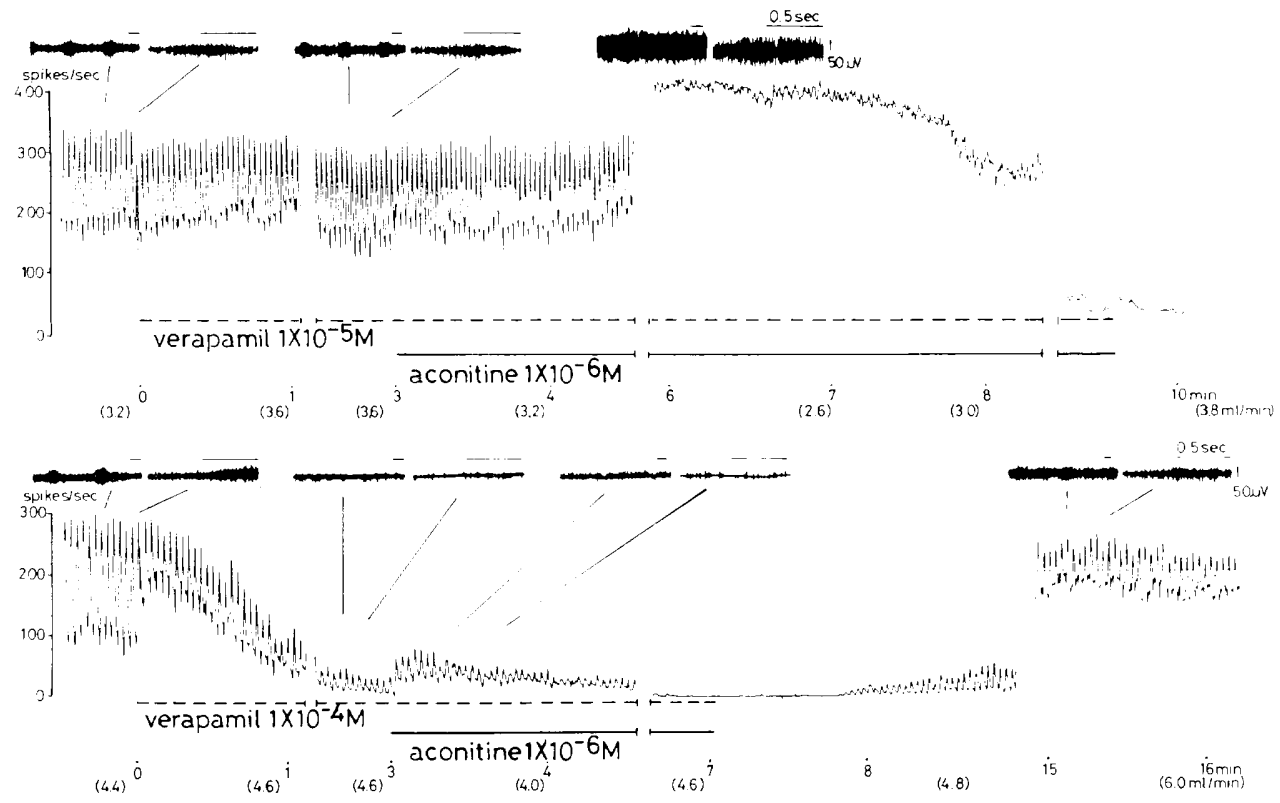

Fig. 7. The effects of aconitine on the rate of afferent discharges from the perfused bullfrog lung inflated with an artificial respirator in the presence of verapamil. For details of legend, see Fig. 2. 
Table 3. Effects of verapamil on the rate of spontaneous afferent discharges and the flow rate of perfusion solution induced by local anesthetics and aconitine

\begin{tabular}{|c|c|c|c|c|}
\hline & \multicolumn{2}{|c|}{$\begin{array}{l}\text { Maximum rate of afferent } \\
\text { discharges (spikes/sec) }\end{array}$} & \multicolumn{2}{|c|}{$\begin{array}{l}\% \text { of the flow rate before } \\
\text { application of local } \\
\text { anesthetics and aconitine }\end{array}$} \\
\hline & $\begin{array}{l}\text { in the presence } \\
\text { of verapamil } \\
\left(1 \times 10^{-5} \mathrm{M}\right)\end{array}$ & $\begin{array}{l}\text { after washing } \\
\text { out of } \\
\text { verapamil }\end{array}$ & $\begin{array}{l}\text { in the presence } \\
\text { of verapamil } \\
\left(1 \times 10^{-5} \mathrm{M}\right)\end{array}$ & $\begin{array}{l}\text { after washing } \\
\text { out of } \\
\text { verapamil }\end{array}$ \\
\hline $\begin{array}{l}\text { Procaine } \\
\qquad 1 \times 10^{-5} \mathrm{M}\end{array}$ & $\begin{array}{l}187.5 \pm 8.5 \\
(93.8 \pm 13.4)\end{array}$ & $\begin{array}{c}218.8 \pm 20.0 \\
(114.6 \pm 20.0)\end{array}$ & $80.9 \pm 3.4^{*}$ & $84.2 \pm 3.2^{*}$ \\
\hline $\begin{array}{l}\text { Procaine } \\
\qquad 1 \times 10^{-4} \mathrm{M}\end{array}$ & $\begin{array}{c}333.3 \pm 14.6 \\
(125.0 \pm 25.5)\end{array}$ & $\begin{array}{c}297.1 \pm 73.3 \\
(104.2 \pm 28.2)\end{array}$ & $72.2 \pm 4.3^{*}$ & $74.7 \pm 3.3^{*}$ \\
\hline $\begin{array}{l}\text { Dibucaine } \\
\qquad 1 \times 10^{-5} \mathrm{M}\end{array}$ & $\begin{array}{l}125.0 \pm 24.2 \\
(57.3 \pm 13.1)\end{array}$ & & $79.2 \pm 2.6^{*}$ & \\
\hline $\begin{array}{l}\text { Dibucaine } \\
\qquad 1 \times 10^{-4} \mathrm{M}\end{array}$ & $\begin{array}{l}255.2 \pm 26.0 \\
(78.1 \pm 19.7)\end{array}$ & & $78.7 \pm 5.4^{*}$ & \\
\hline $\begin{array}{l}\text { Tetracaine } \\
\qquad 1 \times 10^{-6} \mathrm{M}\end{array}$ & $\begin{array}{c}145.8 \pm 57.1 \\
(114.6 \pm 13.4)\end{array}$ & $\begin{array}{c}161.5 \pm 52.0 \\
(109.4 \pm 52.0)\end{array}$ & $89.7 \pm 1.0^{*}$ & $85.7 \pm 1.6^{*}$ \\
\hline $\begin{array}{l}\text { Tetracaine } \\
\qquad 1 \times 10^{-5} \mathrm{M}\end{array}$ & $\begin{array}{l}275.0 \pm 43.4 \\
(75.0 \pm 40.1)\end{array}$ & $\begin{array}{r}304.2 \pm 54.6 \\
(66.7 \pm 13.8)\end{array}$ & $83.1 \pm 3.5^{*}$ & $75.5 \pm 2.2^{*}$ \\
\hline \multirow[t]{2}{*}{$\begin{array}{l}\text { Aconitine } \\
\qquad 1 \times 10^{-6} \mathrm{M}\end{array}$} & $\begin{array}{c}295.8 \pm 42.4 \\
(145.8 \pm 39.9)\end{array}$ & & $84.1 \pm 3.3^{*}$ & \\
\hline & $\begin{array}{l}\text { ir the presence } \\
\text { of verapamil } \\
\left(1 \times 10^{-4} \mathrm{M}\right)\end{array}$ & $\begin{array}{l}\text { after washing } \\
\text { out of } \\
\text { verapamil }\end{array}$ & $\begin{array}{l}\text { in the presence } \\
\text { of verapamil } \\
\left(1 \times 10^{-4} \mathrm{M}\right)\end{array}$ & $\begin{array}{l}\text { after washing } \\
\text { Out of } \\
\text { verapamil }\end{array}$ \\
\hline $\begin{array}{l}\text { Procaine } \\
\qquad 1 \times 10^{-4} \mathrm{M}\end{array}$ & $\begin{array}{c}31.3 \pm 18.9 \\
(10.4 \pm 6.0)\end{array}$ & $\begin{array}{l}182.5 \pm 47.1 \\
(26.0 \pm 15.6)\end{array}$ & $79.5 \pm 3.2^{*}$ & $74.4 \pm 3.3^{*}$ \\
\hline $\begin{array}{l}\text { Dibucaine } \\
\qquad 1 \times 10^{-4} \mathrm{M}\end{array}$ & $\begin{array}{l}31.3 \pm 20.0 \\
(31.3 \pm 6.0)\end{array}$ & & $78.5 \pm 2.7^{*}$ & \\
\hline $\begin{array}{l}\text { Tetracaine } \\
\qquad 1 \times 10^{-5} \mathrm{M}\end{array}$ & $\begin{array}{c}20.8 \pm 20.8 \\
(31.3 \pm 13.4)\end{array}$ & $\begin{array}{l}250.0 \pm 30.8 \\
(20.8 \pm 8.5)\end{array}$ & $84.4 \pm 2.9^{*}$ & $76.3 \pm 5.7^{*}$ \\
\hline $\begin{array}{l}\text { Aconitine } \\
1 \times 10^{-6} \mathrm{M}\end{array}$ & $\begin{array}{c}0 \\
(90.8 \pm 40.3)\end{array}$ & $93.8 \pm 38.5^{b}$ & $92.1 \pm 3.7$ & \\
\hline
\end{tabular}

Each value represents the mean \pm S.E. of four experiments. Value b indicates the maximum rate of spontaneous afferent discharges after washing out of verapamil and aconitine. Number in parenthesis indicates the rate of spontaneous afferent discharges before application of local anesthetics or aconitine in the presence of verapamil. *: $P<0.05$, significantly different from the flow rate obtained before application of local anesthetics or aconitine. Aconitine and dibucaine were applied in the presence of verapamil, but were not applied after washing out of verapamil.

From these results, we considered that the increase in the rate of spontaneous A.D. by procaine and tetracaine would be due to not only the contractile effect of the pulmonary vessel but also to the direct stimulatory effect on the mechanoreceptors which generated the spontaneous A.D. Papaverine $\left(1 \times 10^{-5} \mathrm{M}\right)$ caused the relaxation of the entire lung tissue and inhibited the decrease in the flow rate of perfusion solution induced by these local anesthetics, but did not inhibit the increase in the rate of spontaneous A.D. by local anesthetics, except for dibucaine (Table 2). The maximum rates of spontaneous A.D. increased by procaine $\left(1 \times 10^{-5}-1 \times 10^{-4} \mathrm{M}\right)$ and tetracaine $\left(1 \times 10^{-6}-1 \times 10^{-5} \mathrm{M}\right)$ in the presence of papaverine $\left(1 \times 10^{-5} \mathrm{M}\right)$ were almost the same level as those by reapplication of procaine and tetracaine after washing out of papaverine (Fig. 4 and Table 2). Since procaine at $1 \times 10^{-6} \mathrm{M}$ and tetracaine at $1 \times 10^{-7} \mathrm{M}$ could not cause an increase in the 
rate of A.D. and a decrease in the flow rate of perfusion solution (1), procaine at $1 \times 10^{-5}$ $M$ and tetracaine at $1 \times 10^{-6} \mathrm{M}$ would be almost a minimum concentration to stimulate the receptors which generated the spontaneous A.D. The increase in the rate of spontaneous A.D. induced by dibucaine may result from the contraction of the vessel, since the increase by dibucaine was always accompanied with the decrease in the flow rate of perfusion solution (Tables 1 and 3 ). However, $1 \times 10^{-5} \mathrm{M}$ and $1 \times 10^{-4} \mathrm{M}$ dibucaine decreased the flow rate of perfusion solution to the similar degree in the presence of TTX $\left(1 \times 10^{-7} \mathrm{M}\right)$; high concentration of dibucaine slightly increased the rate of spontaneous A.D. (Table 1). Dibucaine might also have a weak direct stimulatory effect on the mechanoreceptors and would be able to increase the rate of spontaneous A.D. only when the pressure in the vessel was elevated. When dibucaine $\left(1 \times 10^{-5} \mathrm{M}\right)$ was applied in the presence of TTX $\left(1 \times 10^{-7} \mathrm{M}\right)$, the excitability of the receptors on the vessel was suppressed by TTX, and so the increase in the rate of spontaneous A.D. would not appear, regardless of the elevation of the pressure in the vessel.

At the concentration $\left(1 \times 10^{-4} \mathrm{M}\right)$ of verapamil and papaverine which inhibited the generation of A.D. and the stimulatory effects of aconitine on the receptors, the increase in the rate of spontaneous A.D. induced by local anesthetics was inhibited (Figs. 4-7 and Tables 2 and 3 ). The inhibitory effects of verapamil $\left(1 \times 10^{-4} \mathrm{M}\right)$ on the rate of $A . D$. were very similar to those of TTX $\left(1 \times 10^{-7} \mathrm{M}\right)$. Verapamil was reported to reduce the sodium conductance, but has little effect on potassium conductance in squid giant axon (6). The inhibitory effects of verapamil $\left(1 \times 10^{-4} \mathrm{M}\right)$, as well as papaverine $\left(1 \times 10^{-4}\right.$ $M)$, might be due to a local anesthetic activity.

On the other hand, the effects of local anesthetics and aconitine on the rate of A.D. synchronized with lung inflation were different from those on spontaneous A.D. It was found that local anesthetics and aconitine could not increase the rate of A.D. synchronized with lung inflation. While the clear, but partially suppressed increase in the rate of spontaneous A.D. induced by local anesthetics and aconitine appeared in the presence of TTX $\left(1 \times 10^{-7} \mathrm{M}\right)$, papaverine $\left(1 \times 10^{-4} \mathrm{M}\right)$ and verapamil $\left(1 \times 10^{-4} \mathrm{M}\right)$, the rate of A.D. synchronized with lung inflation was decreased by these drugs (Figs. 2-7). From these results, the possibility was excluded that the high frequency impulses of spontaneous A.D. induced by these drugs masked the impulses which were generated during the lung inflation. Procaine and tetracaine which were applied in the presence of TTX $\left(1 \times 10^{-7} \mathrm{M}\right)$, papaverine $\left(1 \times 10^{-4} \mathrm{M}\right)$ or verapamil $\left(1 \times 10^{-4} \mathrm{M}\right)$, abolished all A.D.: but after washing out of these drugs, A.D. synchronized with lung inflation and then spontaneous A.D. reappeared. These results excluded the possibility that the afferent fibers of the receptors which generated A.D. synchronized with lung inflation were so susceptible to local anesthetics that the conduction of the impulses was blocked even if the receptors were stimulated. Aconitine stopped all A.D. irreversiblly when aconitine was applied in normal Ringer's solution. When aconitine was applied in the presence of TTX $\left(1 \times 10^{-7} \mathrm{M}\right)$, papaverine $\left(1 \times 10^{-4} \mathrm{M}\right)$ or verapamil $\left(1 \times 10^{-4} \mathrm{M}\right)$, high frequency spontaneous A.D. appeared, but the rate of A.D. synchronized with lung inflation was very low after washing out of these drugs (Figs. 3, 5 and 7). When the receptors which generated spontaneous A.D. were exposed once to aconitine, the receptor would be depolarized by aconitine. The complete depolarization of the receptor would be inhibited by TTX, papaverine and verapamil, and high excitability of the receptors appeared after washing out of these drugs. A similar phenomenon was observed in frog muscle spindle that the stimulatory effect of aconitine was inhibited by procaine and high frequency discharges appeared after washing out of the two drugs (7). However, it was not thought that the excitability of the receptors which generated the A.D. synchronized with lung inflation was elevated after washing out of both aconitine and TTX, papaverine or verapamil, as compared with that before application of drugs. In normal Ringer's solution, aconitine causes the irreversible conduction blockade in the fibers of the 
receptors. In squid giant axon, it was reported that aconitine irreversibly depolarized and inhibited the excitability of the axon when the axon was stimulated repetitively (8). TTX, papaverine and verapamil would be able to protect the fibers from the depolarizing effects of aconitine. The receptors which generated the A.D. synchronized with lung inflation are thought to be on the lung wall (5) and the afferent fibers of the receptors may be longer than the fibers of the receptors which generate the spontaneous A.D. on the pulmonary vessel (5). We could find a nerve bundle on the lung wall. The fibers which conducted the A.D. synchronized with lung inflation would be susceptible to the conduction blocking effect of aconitine. At present, we cannot clarify the reason why the receptors which generate the A.D. synchronized with lung inflation is insensitive to the stimulatory effects of aconitine and local anesthetics.

We could not define the difference between the stimulatory effects of procaine and tetracaine and those of aconitine on the rate of spontaneous A.D. in the presence of TTX, papaverine or verapamil, except that the stimulatory effects of these local anesthetics were reproducible after washing out these drugs. The effects of local anesthetics on stimulatory actions on the mechanoreceptors are thought to be similar to those of aconitine. Local anesthetics suppress the sodium and potassium conductance and block the nerve conduction by interferring with the conductance changes, but it has been expected that a reduction of potassium conductance would tend to lower the threshold for excitation $(9,10)$. Procaine has been reported to have a depolarizing effect on the pulmonary artery due to the reduction of potassium conductance $(2,3)$. Local anesthetics would lower the threshold for excitation of the receptors due to the reduction of potassium conductance, and finally, local anesthetics would inhibit the excitability of the receptors by interferring with sodium and potassium conductance changes. We reported that 4-aminopyridine (4-AP) caused a long lasting increase in the rate of spontaneous A.D. in the perfused bullfrog lung (5). Since 4-AP was reported to reduce the potassium but not sodium conductance in the squid and cockroach giant axon (11, 12), 4-AP would not decrease the rate of A.D. On the other hand, chlorpromazine (CPZ) was reported to suppress the sodium current much more extensively than the potassium current when it was applied externally in squid giant axon (13). CPZ caused only a decrease in the rate of A.D. from the pulmonary mechanoreceptors (1). We (5) reported that the receptors which generated spontaneous A.D. were not irritant receptors and would be analogous to the juxta-pulmonary capillary receptor (type $\mathrm{J}$ receptor) in the pulmonary capillaries in cats, since the receptors were not stimulated by histamine, but those were significantly stimulated by distension of the vascular wall, and the receptors which generated A.D. synchronized with lung inflation are thought to be a kind of stretchreceptor. Local anesthetics would show a stimulatory followed by inhibitory effect on the receptors which were on the vascular wall of the frog pulmonary vein and have an inhibitory effect on the stretchreceptors which were on the lung wall.

Papaverine and verapamil at high concentration $\left(1 \times 10^{-4} \mathrm{M}\right)$ had a stimulatory effects on the rate of spontaneous A.D. before reduction of it (Figs. 2 and 3 ). Papaverine $\left(1 \times 10^{-5} \mathrm{M}\right)$ relaxed the entire lung tissue. but did not cause a clear increase in the rate of spontaneous A.D.; and verapamil $\left(1 \times 10^{-4}\right.$ $M)$ did not relax the entire lung tissue, but increased the rate of spontaneous A.D. From these results, the increase in the rate of spontaneous A.D. did not result from the relaxation of the pulmonary vessel or entire lung tissue. It was thought that these drugs have direct effects on the pulmonary mechanoreceptors.

The contractile responses to local anesthetics in the entire frog lung was reported by Downes and Taylor (14). In the present experiments, the contractile response of the pulmonary vessel was completely inhibited by papaverine, but not verapamil (Tables 2 and 3). Peiper et al. (15) indicated the mechanisms by which the contraction of the vascular smooth muscle was induced. In their report, the contraction induced by norepinephrine was inhibited by papaverine. but not verapamil, and the mechanism of the 
contraction was suggested to be the release of calcium ion from the tightly bound intracellular calcium fraction. Since the possibility was reported that procaine and norepinephrine affect the same calcium fraction and procaine could release the bound calcium in vascular smooth muscle $(16,17)$, local anesthetics would directly release the calcium ion from the intracellular calcium fraction of frog pulmonary vessel.

\section{References}

1 Kontani, H. and Koshiura, R.: Effects of local anesthetics on the pulmonary mechanoreceptors of the perfused frog lung. Japal. J. Pharmacol. 33, 1096-1099 (1983)

2 Ito, Y., Suzuki, H. and Kuriyama, H.: Effects of caffeine and procaine on the membrane arid mechanical properties of the smooth muscle cells of the rabbit main pulmoriary artery. Japan. J. Physiol. 27, 467-481 (1977)

3 Hara, Y., Kitamura, K. and Kuriyama, H.: Actions of 4-aminopyridine on vascular smooth muscle tissues of the guinea-pig. Br. J. Pharmacol. 68, 99-106 (1980)

4 Wellhoner, H.H.: Effects of aconitine on the slowly adapting stretch receptor neurone of the crayfish. Pfluegers Arch. 304, 104-117 (1968)

5 Kontani, H. and Koshiura, R.: Recording of pulmonary afferent activities from receptors in the perfused lung preparation of bullfrog and effects of drugs on the afferent activity. Japarı. J. Pharmacol. 31, 967-974 (1981)

6 Baker, P.F., Meves, H. and Ridgway, E.B.: Effects of manganese and other agents on the calcium uptake that follows depolarization of squid axons. J. Physiol. (Lond.) 231, 511-526 (1973)
7 Kontani, H., Kudo, Y. and Fukuda, H.: Action of drugs affecting sodium permeability on the muscle spindle of the frog. Folia Pharmacol. Japon. 72, 325-330 (1976) (Abs. in English)

8 Herzog, W.H., Feibel, R.M. and Bryant, S.H.: The effect of aconitine on the giant axon of the squid. J. Gen. Physiol. 47, 719-733 (1964)

9 Ritchie, J.M. and Greengard, P.: Orr the mode of action of local anesthetics. Annu. Rev. Pharmacol. 6, 405-430 (1966)

10 Taylor, R.E.: Effect of procaine on electrica! properties of squid axon membrane. Am. J. Physiol. 196, 1071-1078 (1959)

11 Pelhate, $M$. and Pichon, Y.: Selective inhibition of potassium current in the giant axon of the cockroach. J. Physiol. (Lond.) 243, 90P (1974)

12 Meves, $H$. and Pichon, Y.: Effects of 4-aminopyridine on the potassium current in internally perfused giant axons of the squid. J. Physiol. (Lond.) 251, 60P (1975)

13 Gruener, R. and Narahashi, T.: The mechanism of excitability blockade by chlorpromazine. J. Pharmacol. Exp. Ther. 181, 161-170 (1972)

14 Downes, H. and Taylor, S.M.: A potent, structurally specific stimulant action of procaine in bullfrog lung. Comp. Biochem. Physiol. 72C, 39-43 (1982)

15 Peiper, U., Griebel, L. and Wende, W.: Activation of vascular smooth muscle of rat aorta by noradrenaline and depolarization: Two different mechanisms. Pfluegers Arch. 330, 74-89 (1971)

16 Hudgins, P.M. and Weiss, G.B.: Differentia! effects of calcium removal upon vescular smooth muscle contraction induced by norepinephrine, histamine and potassium. J. Pharmacol. Exp. Ther. 159, 91-97 (1968)

17 Hudgins, P.M.: Some drug effects on calcium movements in aortic strips. J. Pharmacol. Exp. Ther. 170, 303-310 (1969) 